\title{
Diversidad de bacterias endófitas aisladas de árbol de neem y su actividad inhibitoria contra el Colletotrichum gloesporioides causante de la antracnosis del ñame en el departamento de Sucre
}

\author{
Diversity of endophytes bacteria isolated from tree neem and its inhibitory \\ activity against Colletotrichum gloesporioides cause the anthracnose of the \\ yam in the Department of Sucre
}

\author{
D’ Luis R, Luis ${ }^{1}$ Biol, Chamorro A, Leonardo² M.Sc, Pérez C, Alexander² Ph.D. \\ ${ }^{1}$ Universidad de Sucre, Facultad de Educación y Ciencias, Maestría en Biología, Sincelejo, Colombia. \\ ${ }^{2}$ Universidad de Sucre, Grupo Bioprospección Agropecuaria Facultad de Ciencias Agropecuarias, Sincelejo, Colombia.
}

\section{Keywords:}

Endophytes microorganisms; phytopathogens fungi; plant tissues.

\section{Palabras Clave:}

Microorganismos endófitos; hongos fitopatógenos; tejidos vegetales.

\section{Abstract}

The present study as had objective, test in vitro the antifungal endophytes bacteria activity present on leaves and seeds of Neem trees, found into the Sincelejo local area. The tissue samples were recollected randomly. The recollected tissues were superficially sanitized, subsequently, the isolation, counting and distinction of morphotypes of endophytes bacteria were carried out by the Serial dilution technique through the agar plate. Each isolated morphotypes was used to assess in vitro the inhibitory activity of endophytes bacteria cells against the growth of $C$. Gloeosporioides fungus. The activity of the endophytes bacteria against the fungus was determined by inhibition index. The results of the factorial analysis established differences between the amount of bacteria present in leaves and seeds, with higher values in leaves $\left(1,8 \times 10^{10}\right)$ and with lower values in seeds $\left(1,2 \times 10^{9}\right)$. The in vitro assay showed inhibitory activity of endophytic bacteria on fungal mycelial growth, the results of the identification withAPI20E kit confirm with $99,8 \%$ identity of the bacteria species, Pseudomona aeuroginosa, Constituting an isolated endophytic bacteria of the neem tree tissues With inhibitory activity against the mycelial growth of $C$ fungus. Gloeosporioides, causing the disease known as anthracnose of Yam crop in the Sucre department.

\section{Resumen}

El presente estudio tuvo como objetivo, evaluar in vitro la actividad antifúngica de bacterias endófitas presentes en hojas y semillas de árboles de neem, localizadas en el municipio de Sincelejo. Las muestras de los tejidos fueron recolectadas aleatoriamente. Los tejidos recolectados fueron desinfectados superficialmente, posteriormente se llevó a cabo el aislamiento, conteo y separación de morfotipos de bacterias endófitas mediante técnica de dilución seriada sobre superficie del medio agar. Cada morfotipo aislado fue utilizado para evaluar in vitro la actividad inhibitoria bacterias endófitas contra el crecimiento del hongo $C$. gloesporioides. La actividad de las bacterias endófitas contra el hongo fue determinado mediante índice de inhibición. Los resultados del análisis factorial establecieron diferencias entre la cantidad de bacterias presentes en hojas y semillas, encontrándose mayores valores en hojas $\left(1,8 \times 10^{10}\right)$ y menor con respecto a semillas $\left(1,2 \times 10^{9}\right)$. El ensayo in vitro mostró actividad inhibitoria de bacterias endófitas sobre el crecimiento micelal del hongo. Los resultados de la identificación con KIT API20E confirman con un 99,8 \% de identidad con la especie de bacteria Pseudomona aeuroginosa, constituyéndose en una bacteria endófita aislada de tejidos de árbol de neem con actividad inhibitoria contra el crecimiento micelal del hongo C. gloesporioides, causante de la enfermedad conocida como antracnosis del cultivo del ñame en el departamento de Sucre 


\section{INTRODUCCIÓN}

Según los reportes, el vegetal conocido popularmente como árbol de neem se encuentra distribuido por el continente africano, asiático, centro y sur del continente americano y Oceanía, la mayor parte de ellos en el sudeste de Asia y al sur del Sahara. Actualmente en 78 países existe la presencia del árbol de neem y se calcula que en todo el mundo existen entre 64 y 91 millones de ejemplares. En nueve (9) países se utilizan materias activas provenientes de este árbol (RAMOS, 2004). Por otra parte se estima que en Colombia existen más de 100000 árboles de neem, en los departamentos de Huila, Caquetá, Cauca, Nariño, y Antioquia (CAPATAZ et al., 2007), usados con fines investigativos y rurales para el control biológico de plagas. Adicionalmente este árbol tiene usos en reforestación ya que no requiere condiciones ambientales y nutricionales exigentes.

Entre los fitopatógenos asociados a cultivos agrícolas de interés comercial, los hongos fitopatógenos han causado muchas pérdidas en todo tipo de plantaciones $y$, aunque se han venido utilizando un sin número de productos sintéticos para controlarlos, no ha sido posible erradicarlos totalmente. Estos hongos han sido considerados por poseer mecanismos evolutivos muy complejos que les permite adaptarse a nuevas condiciones impuestas por el medio ambiente. Desafortunadamente los productos químicos que se han venido utilizando para el control de este tipo de hongos, han producido un alto impacto ambiental, por su agudo grado de toxicidad y contaminación, además de causar efectos secundarios en las personas que los manipulan, pues los residuos tóxicos se bioacumulan en el organismo generando graves patologías (QUINTERO et al., 2001)

Uno de los productos de importancia socioeconómica y cultural para la costa Caribe colombiana según lo manifiesta OSORIO et al., (2010), es el cultivo del ñame (Dioscorea alata, D. rotundata) el cual tiene su mayor producción en los departamentos de Córdoba, Bolívar y Sucre, constituye cerca del $92 \%$ de la producción nacional y beneficia, aproximadamente, 18,500 familias de pequeños productores. La producción en esta región depende principalmente de las especies $D$. alata y $D$. rotundata, de las cuales la primera especie es altamente susceptible a hongos patógenos del género Colletotrichum. Estos hongos causan al cultivo la antracnosis, una enfermedad conocida por los productores como la quemazón del ñame. Con el término antracnosis se acostumbra designar las enfermedades cuya característica es presentar lesiones típicas necróticas (tejidos muertos) en los tallos, hojas y frutos de las plantas afectadas. Colletotrichum afecta numerosos cultivos y registra en Colombia un alto índice de daños agroeconómicos en todas las áreas productoras. Los informes estadísticos muestran pérdidas hasta de $100 \%$ que dependen de las condiciones de susceptibilidad de los clones, lo cual conlleva un incremento en los costos de producción para los productores (MENDOZA et al., 2007).

En la actualidad existe un gran interés de la comunidad científica a nivel mundial en la búsqueda de nuevas sustancias de origen vegetal o microbiano con actividad antifúngicas, además, se encuentran productos naturales, que, han demostrado efectividad contra fitopatógenos, una alternativa biológica, sostenible y económica que generan un menor impacto ambiental. Se ha demostrado que las bacterias endófitas viven asintomáticamente dentro de los tejidos de la planta y se han encontrado en casi todos los estudios de plantas hasta la fecha (SCHULZ et al., 1993). Ellas juegan un papel importante en las actividades fisiológicas de las plantas hospederas e influyendo en el mejoramiento al estrés y resistencia a enfermedades, insectos y nematodos (CARROLL, 1998; STURZ Y NOWAK, 2000). Los microrganismos endófitos además incrementan el crecimiento de la planta y la capacidad de fijar nitrógeno en la planta hospedera (VERMA et al., 2001; RAHMAN Y SAIGA, 2005). Las bacterias endófitas constituyen una búsqueda invaluable de metabolitos secundarios (LI et al., 2011; STROBEL, 2002) y sería una fuente de nuevos fármacos de importancia biotecnológica y un programa de gestión contra enfermedades de las plantas (MURRAY et al., 1992; BERG et al., 2004).

De acuerdo a lo expresado anteriormente sobre las bacterias endófitas, se consideran esto microorganismos como una nueva estrategia biológica que a futuro pueden ser eficaz contra el manejo de enfermedades en cultivo agrícolas importancia económica para la región. Estas bacterias posiblemente pueden ser usadas como una alternativa de manejo biológico amigables con el ambiente en sustitución a los productos químicos tradicionales utilizados por los productores agrícolas para el control de fitopatógenos. Por lo anterior y con el objeto de dar respuesta a la solución de los problemas fitopatógenos de importancia económica para el departamento de Sucre, se planteó el presente estudio con el propósito de aislar bacterias endófitas asociadas de plantas de neem y evaluar in vitro la actividad antifúngica contra C. gloesporioides causante de la enfermedad conocida como la antracnosis del ñame en el departamento de Sucre.

\section{MATERIALES Y MÉTODOS}

Muestreo. Los sitios (zonas) de muestreos para la recolecta de hojas y semillas de árbol de neem fueron localizados en el municipio de Sincelejo, los cuales correspondierona: Muestra 1: 9 $17^{\prime} 50.4^{\prime \prime} \mathrm{N}+75^{\circ} 23^{\prime} 13.6^{\prime \prime} \mathrm{W}$, 
Muestra 2: $9^{\circ} 17^{\prime} 50.3^{\prime \prime} \mathrm{N}+75^{\circ} 23^{\prime} 13.6^{\prime \prime} \mathrm{W}$, Muestra 3: $9^{\circ} 17^{\prime} 37.4^{\prime \prime} \mathrm{N}+75^{\circ} 23^{\prime} 26.4^{\prime \prime} \mathrm{W}$, Muestra 4: 9०17'09.7"N+75०23'40.4"W, Muestra 5: $9^{\circ} 17^{\prime} 04.1 " N+75^{\circ} 23^{\prime} 47.1$ 'W, Muestra 6: $9^{\circ} 17^{\prime} 13.8$ "N+75०24'41.1"W, Muestra 7: $9^{\circ} 18^{\prime} 33.2$ "N+75 $5^{\circ} 23^{\prime} 22.2$ "W, Muestra 8: $9^{\circ} 18$ '33.1"N+75०23'22.2”W, Muestra 9: $9^{\circ} 18^{\prime} 33.9^{\prime \prime} \mathrm{N}+75^{\circ} 22^{\prime} 56.7^{\prime \prime} \mathrm{W}$. Fueron colectados dos muestreos por cada sitio. Unas muestras constituidas por hojas y semillas fueron depositadas en bolsas estériles, rotuladas y conservadas para el transporte hasta el laboratorio de Investigaciones microbiológicas de la Universidad de Sucre para análisis microbiológico, respectivo. Y la otra parte de las muestras conformadas por hojas, flores y semillas fueron recolectadas y enviadas al laboratorio de Conservación Biológica de la Universidad de Sucre para confirmación de identidad taxonómica a nivel de especie.

Aislamiento de bacterias endófitas. Las muestras de hojas y semillas recolectadas de cada sitio fueron sometidas a proceso de desinfección superficial utilizando metodología propuesta por PÉREZ et al., (2010). El proceso consistió en: dos lavados de hojas y semillas en agua destilada estéril, seguida de agitación por 15 min en solución tampón de fosfato de potasio 0,05 mol.L-1, pH 7,0; inmersión por 1 min en alcohol $70 \%$; agitación por 5 min en solución de hipoclorito de sodio 5\% y Tween $80 \%$; nuevamente se realizó inmersión por 1 min en alcohol $70 \%$ seguida de agitación por 15 min en solución tampón fosfato de potasio 0,05 mol.L-1, $\mathrm{pH}$ 7,0 y, finalmente, se lava cuatro veces en agua destilada esterilizada.

El proceso se repitió dos veces. Para la confirmación del proceso de esterilización de la superficie de los tejidos de hojas y semillas, la alícuota del último lavado se esparció en placa conteniendo medio de cultivo agar $\mathrm{R} 2 \mathrm{~A}$ e incubada a $28^{\circ} \mathrm{C}$ por 72 horas. Seguidamente, cada tejido esterilizado por separado se transfirió a tubos conteniendo caldo de R2A y se incubaron a $28^{\circ} \mathrm{C}$ por 72 horas, para la confirmación de la inexistencia de microorganismos epifíticos en la superficie de los tejidos.

Número de bacterias endófitas por tejidos. Para cuantificar el total de bacterias endófitas, se tomó un g de cada tejido desinfectado, el cual se trituró en nitrógeno líquido. El macerado homogéneo obtenido se transfirió a un tubo con $9 \mathrm{~mL}$ de agua peptona y se agitó vigorosamente. A partir de esta solución se prepararon diluciones seriadas $\left(10^{-1}\right.$ a $\left.10^{-8}\right)$ por triplicado, las cuales se inocularon mediante la técnica de siembra en superficie en el medio agar $\mathrm{R}_{2} \mathrm{~A}$ e incubadas a $28^{\circ} \mathrm{C}$ por 72 horas. La densidad poblacional de bacterias endófitas (UFC/g de raíces) se estimó por conteo directo de colonias en placas. Durante el conteo se observaron y se seleccionaron las colonias que se distinguían en cuanto a forma, aspecto de la superficie, color y tamaño. Los morfotipos seleccionados se purificaron y se conservaron en agar $\mathrm{R}_{2} \mathrm{~A}$ para su posterior análisis bioquímico.

Hongo. El hongo utilizado para el ensayo antifúngico fue aislado a partir de hojas de ñame variedad espino (Dioscorea rotundata) provenientes de cultivos en la vereda Castañeda del municipio de Sincelejo, Sucre, Colombia en las coordenadas 9¹4'54,39"N y $75^{\circ} 21^{\prime} 59,57^{\prime \prime O}$ a $172 \mathrm{msnm}$. Este fitopatógeno fue aislado por el Grupo de Investigación en Bioprospección Agropecuaria en el Laboratorio de Investigaciones Microbiológicas de la Universidad de Sucre y enviado a la Corporación CorpoGen, Ubicado en Bogotá Colombia, para su identificación molecular.

Prueba de actividad antifúngica. Las cepas de $C$. gloesporioides fueron obtenidas del aislamiento de los mismos en cultivos de ñame en el departamento de Sucre. La capacidad de las bacterias para inhibir el crecimiento del hongo fitopatógeno C. gloeosporioides, se realizó mediante ensayos de confrontación y estimación cualitativa. Para ello se sembró el hongo en agar papa dextrosa (PDA) y se dejó crecer durante tres días a temperatura ambiente. Se preparó una combinación de los medios PDA y $\mathrm{R}_{2}$ A en proporción 1:1 para inocular las bacterias endófitas. Al cabo de 2 días de incubación de las bacterias en el medio PDA- $R_{2} A$ a $27^{\circ} \mathrm{C}$, se inoculó el hongo fitopatógeno por el método de siembra directa, se cortaron con sacabocados a partir de la periferia de una colonia de 10 días de crecimiento, cada aislado de aproximadamente $6 \mathrm{~mm}$ de diámetro de área de crecimiento (PÉREZ et al., 2011). Las cajas se incubaron a $30^{\circ} \mathrm{C}$ por 7 días y se utilizó un testigo absoluto sin ningún tipo de tratamiento. Las bacterias endófitas con capacidad de inhibir el crecimiento micelial de aislados del hongo C. gloeosporioides, fueron consideradas como aquellas con actividad antifúngica.

Identificación de bacterias endófitas. Las bacterias con actividad positiva para la actividad antagónica, se identificaron por kit de pruebas bioquímicas API 20E. La batería de pruebas API20E es un sistema de identificación rápida para bacterias de la familia Enterobacteriaceae y otras bacterias Gram-negativas, consta de 21 tests bioquímicos estandarizados y miniaturizados, y una base de datos. Este sistema presenta las ventajas de ser rápido, eficaz y de permitir realizar numerosas pruebas a la vez.

Análisis estadístico. Para el análisis de los datos de densidad poblacional de bacterias endófitas aisladas de diferentes tejidos de árbol de neem por sitios de muestreo, se utilizó un análisis multifactorial para 
determinar correlación entre presencia de bacterias endófitas por tejido y sitio de muestreo.

\section{RESULTADOS}

Clasificación científica del material vegetal. La especie recolectada correspondió a Azadirachta indica A. Juss identificada según voucher 000880.

Aislamiento y densidad de bacterias endófitas. Un total de 30 morfotipos de bacterias endófitas fueron aisladas de hojas y semillas de $A$. indica, recolectadas en nueve sitios (zonas) del municipio de Sincelejo. La densidad poblacional de estas bacterias osciló entre de $1,45 \times 10^{8} \pm 3,25 \times 10^{9}$ por $g$ de tejido. Los resultados del análisis multifactorial llevados a cabo sobre la densidad poblacional en función a sitio de muestreo y tejido analizado, muestran diferencias significativas para cada variable (Tabla 1).

Tabla 1. Análisis multifactorial de densidad poblacional (UFC) de bacterias endófitas en función a sitio de muestreo (zona) y tejido de $A$. indica en el municipio de Sincelejo.

\begin{tabular}{cccccc}
\hline $\begin{array}{c}\text { Fuente de } \\
\text { variación }\end{array}$ & $\begin{array}{c}\text { Suma de } \\
\text { cuadrados }\end{array}$ & gl & $\begin{array}{c}\text { Cuadrado } \\
\text { medios }\end{array}$ & Razón F & Valor-p* \\
\hline Tejidos & $2,18 \times 10^{18}$ & 2 & $1,09 \times 10^{18}$ & 4,02 & $0,0101^{*}$ \\
Sitio & $3,20 \times 10^{18}$ & 2 & $1,02 \times 10^{18}$ & 3,66 & $0,0067^{*}$ \\
Residuos & $4,09 \times 10^{20}$ & 118 & $3,21 \times 10^{18}$ & & \\
Total & $4,40 \times 10^{20}$ & 128 & & & \\
\hline${ }^{*}$ Diferencia altamente significativa con un $95.0 \%$ de nivel de confianza &
\end{tabular}

Los resultados de la prueba múltiple de rango para densidad poblacional de bacterias endófitas por sitio de muestreo, se presentan en la Figura 1. Estos resultados señalan que el sitio 5 (zona 5), presentó las mayores densidades poblacionales $\left(3,25 \times 10^{9} \mathrm{UFC} / g\right.$ de tejido), con respecto a los demás sitios de muestreos (zonas). Los datos presentados señalan que en el sitio 3 (zona 3), se encontraron las menores densidades poblacionales de bacterias endófitas (1,45 ×10 UFC/g de tejido).

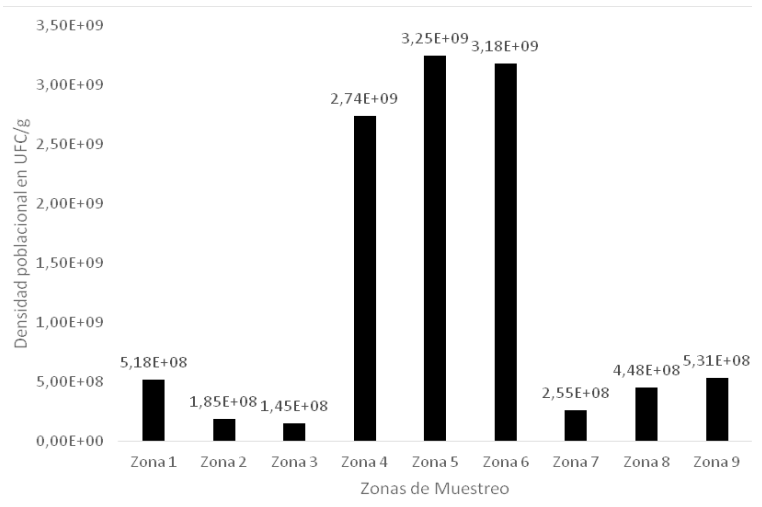

Figura 1. Resultados prueba múltiple de rango para densidad poblacional de bacterias endófitas en función a las zonas de muestreo en el municipio de Sincelejo.
La prueba múltiple de rangos para densidad poblacional de bacterias endófitas con respecto a tejido vegetal, como se observa en la Figura 2, muestra diferencias con respecto a tipo de tejido recolectado, señalando mayores densidades para el tejido hojas $\left(1.8 \times 10^{10}\right.$ UFC/g de tejido) con respecto a semilla $\mathrm{r}\left(1.20 \times 10^{9}\right.$ UFC/g de tejido).

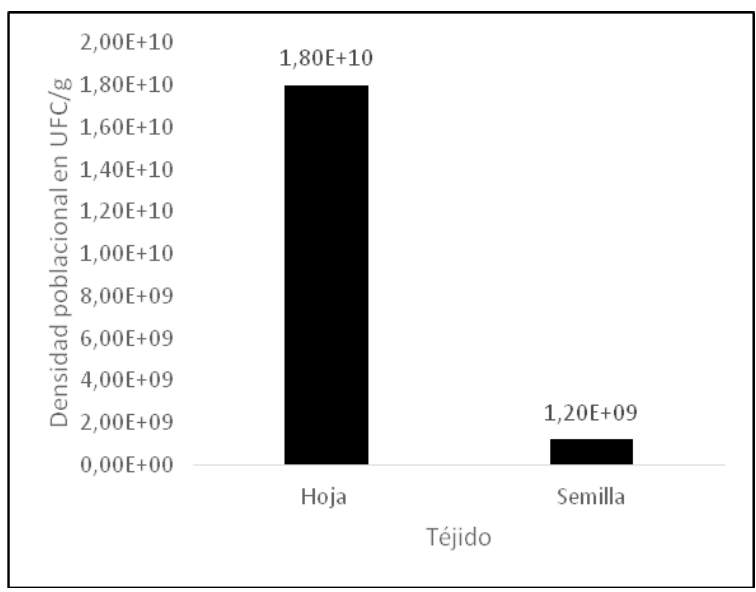

Figura 2. Prueba múltiple de rango para densidad poblacional de bacterias endófitas en función a tejidos de $A$. indica ubicado en el municipio de Sincelejo, Colombia 2016.

Hongo. Los resultados del análisis molecular realizados por el laboratorio CorpoGen de la ciudad de Bogotá, la cepa objeto de estudio, mostró un $100 \%$ de identidad de su longitud con secuencias de ITS, con secuencias almacenadas en banco genómicos mundiales correspondiendo a la especie Colletotrichum gloeosporioides.

Actividad antifúngica. Un total de 30 bacterias endófitas fueron aisladas de tejidos de árbol de neem y de acuerdo a los resultados de la actividad inhibitoria in vitro, el aislado $\mathrm{NH}_{2}$ GIBA mostró actividad antifúngica contra $C$. gloesporioides. En la Figura 3, se observa, la actividad inhibitoria contra el crecimiento micelial del hongo.

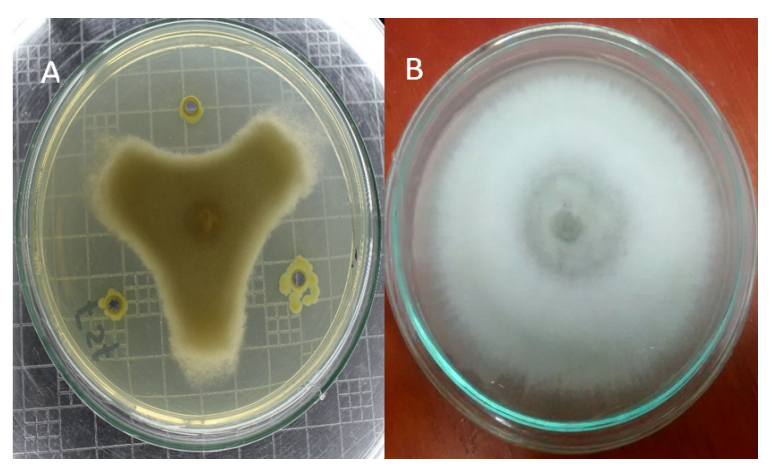

Figura 3. Prueba de actividad antifúngica de la bacteria endófita $\mathrm{NH}_{2}$ GIBA contra C. gloesporioides. $\mathrm{N}$ : neem, $\mathrm{H}_{2}$, hoja mortotipo 2, GIBA: grupo de investigación en Bioprospección Agropecuaria. Fuente De Luis, Chamorro y Pérez, 2016. 
Identificación de las bacterias endófitas. De acuerdo al sistema de identificación API 20 E se identificó la bacteria Pseudomona aeuroginosa con actividad antifúngica, de acuerdo a la literatura esta bacteria pertenece a la familia Pseudomonadaceae y es un bacilo gramnegativo aerobio, es un microorganismo común en el medio ambiente y puede encontrarse en las heces, el suelo, el agua y las aguas residuales. Puede proliferar en ambientes acuáticos, así como en la superficie de materias orgánicas propicias en contacto con el agua (DE VICTORICA Y GALVAN, 2001).

\section{DISCUSIÓN}

Las diferentes revisiones de literaturas en revistas especializadas nacionales e internacionales no reportan la presencia de bacterias endófitas asociadas con especie vegetales de $A$. indica y menos aún estudios que soporten la actividad antifungicas asociadas a esta especie vegetal contra el crecimiento micelial de C. gloesporioides. De otra parte trabajos llevados a cabo por DONCEL et al., (2016) sobre la diversidad de bacterias endófitas asociadas a diferentes tejidos de pasto colosoana en el departamento de Sucre, han confirmado la presencia de $P$. aeuroginosa como una bacteria endófita con capacidad in vitro de fijar biológicamente nitrógeno y solubilizar fosfatos.

Sin embargo, diversos estudios de bacterias endófitas aisladas de otras especies vegetales han comprobado actividad antimicrobiana de estas bacterias con fitopatógenos de cultivos agrícolas de interés comercial a nivel internacional. De otra parte se ha manifestado que las bacterias endófitas son considerados microorganismos con actividad inhibitoria contra diversos patógenos y la eficiencia de esta actividad según lo han demostrado diversos estudios, es debido a que los microorganismos endófitos pueden establecer una relación mutualista con la planta desde su interior, mediante el cual les confieren protección contra factores bióticos y abióticos adversos (SCHULZ y BOYLE 2006), promueven el crecimiento en las plantas (TSAVKELOVA et al., 2007), aumentan la resistencia a enfermedades (CHANWAY, 1998), contribuyen a la fijación biológica de nitrógeno (JIMENEZ et al., 1997; ESTRADA et al., 2002), bioremediación (NEWMAN Y REYNOLDS, 2005) y producción de sideróforos o inmunidad (SESSITSCH et al., 2002).

El principal rol de las bacterias endófitas en las actividades fisiológicas de la planta hospedera está influenciada por un aumento de la resistencia a condiciones de estrés del ambiente, insecto, nematodos y enfermedades. Las endófitas pueden también acelerar el crecimiento de las plantas y las capacidades de fijación de nitrógeno y la movilización de elementos como el fosforo. Constituyen una fuente incalculable de metabolitos secundarios y de fuente de nuevas drogas de importancia biotecnológica y de programas para el manejo de enfermedades de las plantas. La eficacia de los endófitos como agentes de control biológico depende de muchos factores: la especificidad del huésped, la dinámica de la población y el patrón de colonización, la capacidad de moverse dentro de los tejidos del huésped, y la capacidad de inducir resistencia sistémica (MELNICK et al., 2008).

Otros trabajos llevados a cabos, han señalado, que la eficacia de los endófitos como agentes de control biológico está relacionado a diferentes aspectos como: la especificidad del huésped, la dinámica poblacional y el patrón de colonización, la capacidad de moverse dentro de los tejidos del huésped, y la capacidad de inducir resistencia sistémica. Por ejemplo, la cepa de Pseudomona sp. PsJN una bacteria endófita identificada en plantas de cebolla, inhibe el crecimiento del hongo Botritis cinérea reduciendo su crecimiento y para luego colonizar los tejidos de estas plantas (BARKA et al., 2002). Sin embargo estudios realizados por ALEMANY, (2001), han reporta la presencia del compuesto 2,4-Diacetilfluoroglucinol en P. fluorescens, quien ha demostrado actividad de inhibición del 69,2\% en el crecimiento de la cepa del hongo Colletotrichum sp. Del mismo modo, SANTOYO et al., 2010 han demostrado experimentalmente que la cepa ZUM 80 de $P$. fluorescens tiene capacidad de inhibir el crecimiento micelial de $C$. lindemuthianum y $C$. gloesporioides en un 72 y $76 \%$ respectivamente, debido a la producción de sideróforos de esta cepa bacteriana.

Por no existir estudios que permitan comparar los resultados obtenidos en el presente estudio, las especie de bacteria $P$. aeuroginosa se convierte en la primera evidencia de bacterias endófitas con capacidad de inhibir al crecimiento micelial del hongo C. gloesporioides, y futuro después de otros estudios in vivo, podrían ser una especie como alternativa de un nuevo bioinsumo contra el hongo causante de la enfermedad conocida como antracnosis del ñame, para el departamento de Sucre.

\section{Conclusión}

Los resultados obtenidos en el presente estudio muestran mayores densidades poblacionales de bacterias endófitas de árbol de neem para el sitio de muestreo 5 (zona 5) del municipio de Sincelejo. Del total de 30 aislados de bacterias endófitas aisladas y separadas según forma, morfología, color, tipo de tejido utilizado y sitio de muestreo (zonas), solamente el morfotipo identificado como $P$. aeuroginosa mostró in vitro actividad inhibitoria contra el crecimiento micelial de C. gloesporioides causante de la antracnosis en 
ñame, lo que posiblemente a futuro podría ser utilizada como una alternativa biológica para el manejo de esta enfermedad en campo. Próximos estudios in vivo, permitirá evaluar la actividad de $P$. aeuroginosa contra C. gloesporioides y determinar en condiciones edafoclimáticas de la región, el comportamiento de dicha bacteria como potencial biológica para el manejo de la enfermedad. Así mismo, estudios moleculares posteriores verificara la identidad a nivel de especie y los posibles genes y actividades biológicas de esta bacteria implicada en dicha actividad y su uso como una alternativa amigable para el medio ambiente.

\section{Agradecimientos}

Los autores y la Universidad de Sucre, expresan sus agradecimientos anla Gobernación de Sucre y al Fondo Nacional de Ciencias, Tecnología e Innovación (CTe I) del Sistema general de regalías- SGR, por el otorgamiento de recursos económicos con destinos al departamento de Sucre para la ejecución de las actividades de Ciencia, Tecnología e Innovación en el marco del proyecto denominado "Implementación de un programa para el desarrollo de productos biotecnológicos para el sector agrícola en el Dpto de Sucre", CODIGO BPIN 2013000100022 y al Departamento de Sucre por todo el apoyo brindado.

\section{REFERENCIAS}

ALEMANY, J. 2001. Caracterización de metabolitos producido por cepas de Pseudomona fluorescens efectivas en el control biológico de hongos fitopatógenos. Tesis doctoral. Universidad de Girona. Departamento de Ingeniería química; Tecnología agroalimentaria. Instituto de tecnología Agroalimentaria. Girona, España.

BARKA, E.A.; GOGNIES, S.; NOWAK, J.; AUDRAN, J.C.; BELARBI, A. 2002. Inhibitory effect of endophytic bacteria on Botrytis cinerea and its influence to promote the grapevine growth. Biological Control 24: 135-142.

BERG, G.; KRECHEL, A.; FALTIN, F.; ULRICH, A.; HALLMANN, J.; GROSCH, R. 2004. Endophytes: a new source for environmental biotechnology. In: Abstracts of 10th international symposium on microbial ecology ISME-10, "Microbial Planet: sub surface to space", Cancun, Mexico. August 22-27.

CAPATAZ, J.; OROZCO, F.; VERGARA, R.; HOYOS, R. 2007. Efecto antialimentario de los extractos de suspensiones celulares de Azadirachta indica sobre Spodoptera frgiperda J.E Smith en condiciones de laboratorio. Revista Fac. Nal. Medellin. 60(1): 3715-3715.

CARROLL, G. 1988. Fungal endophytes in stems and leaves: from latent pathogens to mutualistic symbionts. Ecology. 69:2-9.

CHANWAY, C. 1998. Bacterial endophytes: ecological and practical implications. Sydowia.50:149-170.

DE VICTORICA, J.; GALVÁN, M. 2001: Pseudomonas aeruginosa as an indicator of health risk in water for human consumption. Water Science and Technology, 43:49-52.

DONCEL, A.; CHAMORRO, L.; PERÉZ, A. 2016. Actividad in vitro de bacterias endófitas promotoras de crecimiento asociadas con pasto colosoana en el municipio de Corozal, Sucre. Rev Colombiana Cienc Anim. 8:351-360.

ESTRADA, P.; MAVINGUI, P.; COURNOYER, B.; FONTAINE, F.; BALANDREAU, J.; CABALLERO, J. 2002. A N2-fixing endophytic Burkholderia sp. associated with maize plants cultivated in Mexico. Canadian Journal of Microbiology.48: 285-294.

JIMÉNEZ, T.; FUENTES, L.; TAPIA, A.; MASCARUA, M.; MARTINEZ, E.; CABALLERO, J. 1997. Coffea arabical. a new host plant for Acetobacter diazotrophicus, and isolation of other nitrogen-fixing acetobacteria. Applied Environmental Microbiology. 63:3676-3683.

LI, J.Y.; STROBEL, G.A.; HARPER, J.K.; LOBKOVSKY, E.; CLARDY, J. 2000. CRYPTOCIN, a potent tetramic acid antimycotic from the endophytic fungus Cryptosporiopsis of quercina. Org Lett. 2: 767-770. 
MELNICK, R.; ZIDACK, N.; BAILEY, B.; MAXIMOVA, S.; GUILTINAN, M.; BACKMAN, P. 2008. Bacterial endophytes: Bacillus spp. from annual crops as potential biological control agents of black pod rot of cacao. Biological Control 46:46-56.

MENDOZA, C.; MORENO, A.; WEIL, M.; ELANGO, F. 2007. Evaluación del efecto de extractos vegetales sobre el crecimiento in vitro de Phytophtora palmivora butl. Y Colletotrichum gloesporioides (Penz) Penz. Y Sacc. Tierra Trop. 3(1): 81-89.

MURRAY, F.R.; LATCH, G.C.M.; SCOTT, D.B. 1992. Surrogate transformation of perennial ryegrass, Lolium perenne, using genetically modified Acremonium endophyte. Mol Gen Genet. 233:1-9.

NEWMAN, L.; REYNOLDS, C. 2005. Bacteria and phytoremediation: new uses for endophytic bacteria in plants. Trends in Biotechnology.23 (1): 6-8.

OSORIO, J.; BUSTAMANTE, E.; MACARENO, M.; HERNÁNDEZ, E.; BELTRÁN, J. 2010. Aislamientos enzimáticos de protoplastos a partir de mesófilo de Dioscorea alata cultivar "Pico de Botella". Temas Agrarios. 15(1):58-70.

PÉREZ, C.; ROJAS, J.; FUENTES, C. 2010. Diversidad de bacterias totales y endófitas asociadas a raíces del pasto Bothriochloa pertusa (L) A. Camus. Revista Colombiana de Ciencia Animal. 2(1): 58-72.

PÉREZ, A.; ROJAS, J.; ANAYA, L.; PÉREZ, K. 2011. Evaluación in vitro de la actividad inhibitoria de extractos vegetales sobre aislados de Colletotrichum spp. Acta Agron. 60(2):158-164.

QUINTERO, S.R.; GIOANETTO, F.; CHÁVEZ, C.E.; BÁRCENAS, O.D. 2001. Curso taller de agricultura orgánica. Universidad Autónoma De Chihuahua: CIDACOM, Chihuahua, Chihuahua.

RAHMAN, M.H.; SAIGA, S. 2005. Endophytic fungi (Neotyphodium coenophialum) affect the grow than mineral uptake, transport and efficiency ratiosint all fescue (Festuca arundinacea). Plant Soil. 272:163-71.

RAMOS, C.; GONZÁLEZ, V.; SOTO, M.; ENGLEMAN, E.; RODRÍGUEZ, D. 2004. Variación en contenido de Azadiractina en frutos de margosa durante su desarrollo. Revista Fitotecnica Mexicana. 27 (1): 81-85.

SANTOYO, G.; VALENCIA, E.; OROZCO, M.; PEÑA, J.; FARÍAS, R. 2010. Papel de los sideróforos en la actividad antagónica de Pseudomonas fluorescens ZUM80 hacia hongos fitopatógenos. Revista Terra Latinoamericana. Vol 28. N 1 pag: 53-60.

SESSITSCH, A.; REITER, B.; PFEIFER, U.; WILHELM, E. 2002. Cultivation independent population analysis of bacterial endophytes in three potato varieties based on eubacterial and Actinomycetes-specific PCR of 16S rRNA genes. FEMS Microbiology Ecology. 39:23-32.

SCHULZ, B.; WANKE, U.; DRAEGER, S. 1993. Endophytes from herbaceous and shrubs: effective ness of surface sterilization methods. Mycol Res. 897: 1447-1450.

STROBEL, G.A. 2002. Rainforest endophytes and bioactive products. Crit Rev Biotechnol, 22: 325-33.

STURZ, A.V.; NOWAK, J. 2000. An endophytic community of rhizobacteria and the strategies requires to created yield enhancing associations with crops. Appl Soil Ecol. 15: 183-190.

TSAVKELOVA, E.; CHERDYNTSEVA, T.; BOTINA, S.; NETRUSOV, A. 2007. Bacteria associated with orchid roots and microbial production of auxin. Microbiological Research. 162: 69-76.

VERMA, S.C.; LADHA, J.K.; TRIPATHI, A.K. 2001. Evaluation of plant growth promoting and colonization ability of endophytic diazotrophs from deep-water rice. J Biotechnol. 91: 127-41. 